\title{
TRAP Complex
}

National Cancer Institute

\section{Source}

National Cancer Institute. TRAP Complex. NCI Thesaurus. Code C19890.

The human thyroid hormone receptor-associated protein (TRAP)-Mediator complex was

originally identified as a large multimeric complex that copurifies with the thyroid

hormone receptor (TR) from HeLa cells and markedly enhances TR-mediated

transcription in vitro. More recent studies have implicated TRAP-Mediator as a

coactivator for a broad range of nuclear hormone receptors as well as other classes of

transcriptional activators. TRAP-Mediator may play an important coregulatory role in

androgen receptor-mediated gene expression. (from J Biol Chem. 2002;277:42852-8) 